\section{Update on innovation and compliance measurement in compression therapy}

\author{
Yung-Wei Chi \\ Vascular Center, University of \\ California, Davis - Sacramento, CA, \\ USA
}

\section{Introduction}

Compression therapy is central to the care of patients with chronic venous insufficiency, and its efficacy relies on one's adherence to treatment. Up to now, compliance has only been measured by subjective verbal feedback from patients and quantifying such feedback remains to be elucidated. The study from Raju et al. ${ }^{1}$ and the SOX trial $^{2}$ have determined adherence to compression therapy is at best mediocre. Its with this historical background, technological advances may provide potential tools to help healthcare providers to better measure compliance in compression therapy in a meaningful way.

\section{Materials and Methods}

The Thermotrack $\AA^{3}$ (Figure 1) device is a miniaturized temperature sensing device encased in a stainless steel case, 16x6 mm. It started out in the food service industry and with some ingenuity, it can be sewn into the seams of compression stockings and therefore determines temperature variation between the body surface and the environment reflecting usage. Temperature variations are recorded in a local memory chip and can be interrogated when the Thermotrack ${ }^{\circledR}$ is retrieved after certain period of compression stocking use i.e. 3 or 6 months. Unfortunately, in order to retrieve it for interrogation, the compression stocking has to be cut open. Its size, accuracy and long battery life are its advantages. On the other hand when outside temperature reaches above $23^{\circ} \mathrm{C}$ or $74^{\circ} \mathrm{F}$, the Thermotrack ${ }^{\circledR}$ device becomes unreliable. The VenoSense $($ p pressure device (Figure 1) is another technological advancement using pressure variation when the compression stocking is placed on the body surface to reflect usage. The mechanism of pressure sensing has been previously published using piezoresistive sensing principle. ${ }^{4}$ It is a larger size device enclosed in a plastic case, $41.5 \times 13.5 \mathrm{~mm}$, and can be miniaturized and sewn into the seams of compression stockings similar to Thermotrack ${ }^{\circledR}$.
Unlike Thermotrack ${ }^{\circledR}$ in which usage data are stored locally, VenoSense $(C)$ pressure device communicates wirelessly by way of Bluetooth ${ }^{\circledR}$ and connects to iOS based modules via a proprietary app and all data are stored in the cloud. Interrogation can be made wirelessly in real-time and eliminates the need to damage the stocking. Advantages include those characteristics similar to Thermotrack ${ }^{\circledR}$ except size however, its performance accuracy is not affected by outside temperature variations.

\section{Results}

Both the Thermotrack ${ }^{\circledR}$ and VenoSense $C$ pressure devices are advances in quantifying compliance in compression therapy. Their mechanical performance and characteristics are illustrated in Table 1.

Table 1. System performance.

\begin{tabular}{|c|c|c|}
\hline & Thermotrack@ & VenoSense@ \\
\hline Mechanism & $\begin{array}{l}\text { Temperature }-40^{\circ} \mathrm{C} \text { to } 80^{\circ} \mathrm{C} \\
\text { (unreliable when external } \\
\text { temperature }>23^{\circ} \text { or } 74^{\circ} \mathrm{F} \text { ) }\end{array}$ & $\begin{array}{l}\text { Pressure }>5 \mathrm{mmHg} \\
\text { (temperature independent) }\end{array}$ \\
\hline Date rate & 1 data/20 min & 1 data/15 to $20 \mathrm{~min}$ \\
\hline Battery life & 10 years (product insert) & 6 months \\
\hline Battery & Lithium & Lithium \\
\hline Contact surface material & Case & Foam \\
\hline Communication interface & Local storage - USB & Local storage $+/$ - wireless \\
\hline Waterproof & Yes & Yes \\
\hline
\end{tabular}

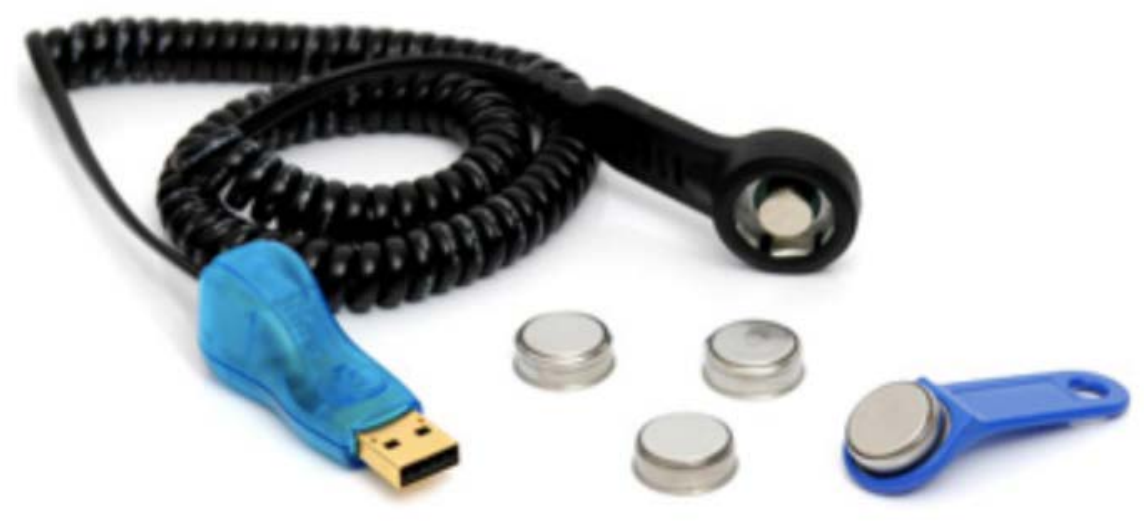

Figure 1. Thermotrack and VenoSense $\bigodot$ pressure devices.
Correspondence: Yung-Wei Chi, Vascular Center, University of California, Davis Sacramento, CA, USA.

E-mail: ywchi@ucdavis.edu

Conflict of interest: Dr. Chi is a shareholder of VenoSense, Inc.

Conference presentation: International Compression Club (ICC) Meeting, Paris, 2017. Commons Attribution 4.0 License (by-nc 4.0).

(C) Copyright $Y-W$. Chi , 2018

Licensee PAGEPress, Italy

Veins and Lymphatics 2018; 7:7638

doi:10.4081/vl.2018.7638

\section{Conclusions}

The field of quantifying compliance may be gradually moving away from subjective verbal feedback to objective com-
This work is licensed under a Creative 
munication thru technological advances. This has the potential to positively impact both clinical outcome and healthcare savings.

\section{References}

1. Raju S, Hollis K, Neglen P. Use of com- pression stockings in chronic venous disease: patient compliance and efficacy. Ann Vasc Surg 2007;21:790-5.

2. Kahn SR, Shapiro S, Wells PS, et al. Compression stockings to prevent postthrombotic syndrome: a randomised placebo-controlled trial. Lancet 2014;383:880-8.

3. Uhl JF, Benigni JP, Chahim M, Frederic D. Prospective randomized controlled study of patient compliance in using a compression stocking: importance of recommendations of the practitioner as a factor for better compliance. Phlebology. 2018 Feb;33(1):36-43.

4. Chi YW, Tseng KH, Li R, Pan T. Comparison of piezoresistive sensor to PicoPress(R) in in-vitro interface pressure measurement. Phlebology. 2018 Jun;33(5):315-320. 